PROBLEMS

OF EDUCATION

IN THE $21^{\text {st }}$ CENTURY

Volume 50,2012

\title{
OPEN PROBLEMS IN MATHEMATICAL MODELLING AND PHYSICAL EXPERIMENTS. EXPLORING EXPONENTIAL FUNCTION
}

\author{
Raffaele Pisano \\ SCité, University of Lille1, France/RCTHS, Pilsen University, Czech Republic \\ E-mail: pisanoraffaele@iol.it \\ Paolo Bussotti \\ Enriques National Edition, Livorno, Italy \\ E-mail: paolo.bussotti@alice.it
}

\begin{abstract}
Generally speaking the exponential function has large applications and it is used by many non physicians and non mathematicians, too. Nevertheless some crucial and practical problems happen for its mathematical understanding. Mostly, this part of mathematical cognitive programmes introduce it from the mathematical strictly point of view. On the contrary, since both physics experiments make a vast use of it, in this paper the exponential function will be explained starting from physical experiments and only later a mathematical modelling of it will be organized. The relationship physics-mathematics-geometry is crucial and indispensable in this kind of integrated and history\&science education. The history and epistemology of mathematics and physics can be a significant means to make the epistemological and didactical research more profound and clear.
\end{abstract}

Key words: interdisciplinary, elementary functions, geometric transformations, epistemological teaching, thermology and calorimetry.

\section{Introduction}

The relation between mathematics and experimental results is one of the complex problems in physics and mathematics teaching. ${ }^{1}$ A historical and epistemological point of view is suggested. Several authors - physicians, historians and philosophers of science - tried to supply a general theory. Someone gave the prominence to the experimental-operative bases, i. e. one can see some Mach's reasonings (Mach, [1883]2009) or to the operational character of the concepts used in physics (Bridgman); while others underlined the necessitating character of the mathematical principles of the physics and of their consequences (Lagrange [1788]1888; Laplace, 1799-1825; see also Fox, 1974). Fourier himself, in his studies on the heat resorted to an analytical approach without considering the nature of heat/experiments (Fourier, 1807, 1822). Nevertheless, other important research fields were born without a priori a mathematical structure: Sadi Carnot's Réflexion sur la puissance motrice $d u$ feu and his father Lazare on mechanics (Carnot S, 1824; Carnot L 1813; Pisano, 2010; Gillispie and Pisano, 2012), and Faraday's Experimental Researches in Electricity (Faraday, 1839-1855) are eminent examples. Faraday without formulas introduced the bases for the concepts of field and

1 Generally speaking on that one can see: Ball, Thames, Phelps, 2008; Bass, 2005. Boero and Guala, 2008). Boero, Pedemonte and Robotti 1997; Debru, 1997; Freudenthal, 1973. George and Velleman, 2002; Lakoff and Nunez, 2000; Meltzoff, Kuhl, Movellan and Sejnowski 2009; Osborne and Collins, 2003). 
vectors in electromagnetic induction theory (Pisano, 2013). Differently, in late (electrothermal and) electromagnetic theory an advanced use of mathematics was presented (1864-1873) by Maxwell \begin{tabular}{|l} 
PROBLEMS \\
OF EDUCATION \\
IN THE 21 $1^{\text {st }}$ CENTURY \\
Volume 50, 2012
\end{tabular} (Maxwell, 1865, 1873) and mechanically (vortex) explain Faraday's phenomena. On the other hand, the work of Newton himself is very interesting from this point of view: Newton in his Principia (Newton, [1687]1803; presents the treatment of the subjects in an almost-Euclidean form, while the Optiks (Newton [1704]2003) has an explicit experimental basis.

From a historical point of view, it is enough to remind the reader the plurality of interpretations inherent to Galileo (Galileo, 1890-1909; Pisano, 2009) many scholars underlined the experimental tendencies of Galileo, others the importance he ascribed to mathematics, others attempted to provide a synthesis, e.g. in his Archimedean mechanics (Pisano and Bussotti, 2012). It looks reasonable to claim that a general theory of the relation between mathematics and experiments inside physics cannot be provided coherently, but, at most, one can speak of tendencies prevailing according to authors, problems and historical epochs.

The discipline in which physics and mathematics work in unison is usually called mathematical physics. Nevertheless a recent study concerning the mathematical and physical objects within a scientific theory is provided by one of us (Pisano, 2013, 2011a, 2011b) producing a different historical approach: physics mathematics (see also Alvarez and Dhombres, 2011). It is not a mathematical application of physics or vice-versa, but rather a new way to work with science:

1) New methodological approach to solve physical (in origin) problems where the quantities may be physical and mathematical at the same time (first novelty);

2) Measurements are not a priority or a prerogative (second novelty) to make a coherent physical science.

The physics mathematics resorts to all complex instruments typical of mathematical analysis, with its tissue of functions and differential equations. A function which occurs to explore many nonlinear physical phenomena is the exponential function. It represents hence an important part of physical mathematical modelling. From a science education point of view, a classical procedure consists in introducing the mathematical properties of exponential function and to apply them in order to solve the physical problems where this function appears. If the study of some phenomena - like the cooling of a liquid - needs the solution of differential equations and in the last but one year of secondary school (in which the cooling is analysed) this equation have been not yet studied, the teacher provides the results without a demonstration. Here a different approach is proposed, by which it is possible to hypothesize the form of the cooling curve of the water on the basis of experimental data and, from these hypotheses, we will try to come back to the mathematical properties of the exponential function. We could speak of an experimental approach to mathematical physics. In connection to this, some problems inherent to the general relation between induction and deduction will be dealt with.

\section{Methodology of Research: the Curves}

The following work is within physics and mathematics integrated teaching. It is organized in four main steps: 
PROBLEMS

OF EDUCATION

IN THE $21^{\text {st }}$ CENTURY

volume 50,2012

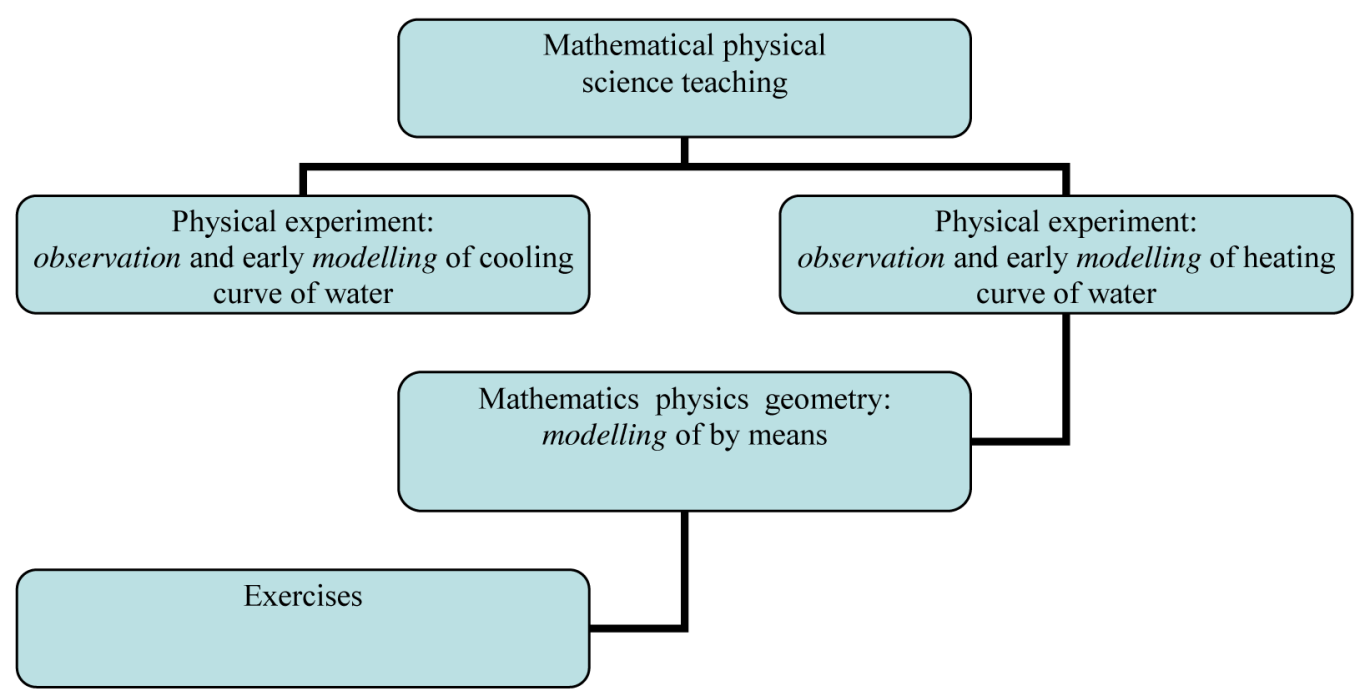

Figure 1: A cognitive and scientific modelling process.

In the following we present some general background items

Table 1. A concise didactical and pedagogical process.

\begin{tabular}{|l|l|}
\hline Background knowledge & $\begin{array}{l}\text { - Knowledge of the properties of physical quantities } \\
\text { - Concept of measurement of a physical quantity } \\
\text { - Knowledge of algebraic operations } \\
\text { - Knowledge of the concept of function } \\
\text { - Study of a Cartesian graph (and PV-Clapeyron) } \\
\text { - Applicability of the principle of conservation of mechanical energy } \\
\text { - Study of proportionality between variables } \\
\text { - Trigonometry } \\
\text { - Concept of a continuous function } \\
\text { - Geometric transformations } \\
\text { - Distinguish mechanical phenomena of the phenomena of heat }\end{array}$ \\
\hline Cognitive objectives & - enon (e.g.) whose performance is not linear \\
- Enhance the laboratory experiences having simple devices \\
- Propose an associative logic-inductive \\
- Qualitative and intuitive approach to the concept of limit \\
- Reinforce the learning of the study of continuous functions \\
- Qualitative and intuitive approach to the concept of asymptote \\
- Mathematically study the thermal phenomena and the phenomena of heat \\
- Distinction between physical and mathematical functions \\
- Study of the variation (without the use of derivative) of the exponential function \\
- Calculus of the heat work \\
- Calculus of the efficiency of a heat engine \\
- Measurements of temperatures
\end{tabular}




\begin{tabular}{|c|c|c|}
\hline & & $\begin{array}{l}\text { PROBLEMS } \\
\text { OF EDUCATION } \\
\text { IN THE } 21^{\text {st }} \text { CENTURY } \\
\text { Volume 50, } 2012\end{array}$ \\
\hline Operative objectives & $\begin{array}{l}\text { - The mathematical function such as exponential representation of a physical not linear } \\
\text { phenomenon } \\
\text { - Enhance the laboratory experience poor } \\
\text { - Propose an associative logic-inductive } \\
\text { - Qualitative and intuitive approach to the concept of limit } \\
\text { - Reinforce the learning of the study of continuous functions } \\
\text { - Qualitative and intuitive approach to the concept of asymptote } \\
\text { - Mathematically study the thermal phenomena and the phenomena of heat } \\
\text { - Distinction between the physical and mathematical functions } \\
\text { - Study of the variation (without the use of derivative) of the exponential function } \\
\text { - Calculate the thermal work } \\
\text { - Calculate the efficiency of a heat engine } \\
\text { - Take measurements }\end{array}$ & \multirow[t]{5}{*}{59} \\
\hline Range & 6 hours & \\
\hline Classroom Level & Last one before going to university & \\
\hline $\begin{array}{l}\text { Methodologies and } \\
\text { supports }\end{array}$ & $\begin{array}{l}\text { Brainstorming, workflow, traditional lectures, problem solving, historical issues, laborato- } \\
\text { ries experiments, books and speeches }\end{array}$ & \\
\hline Interdisciplinary & $\begin{array}{l}\text { Mathematics, physics, geometry; history and epistemology of physical and mathematical } \\
\text { sciences }\end{array}$ & \\
\hline
\end{tabular}

\section{Instrument and Procedures ${ }^{2}$}

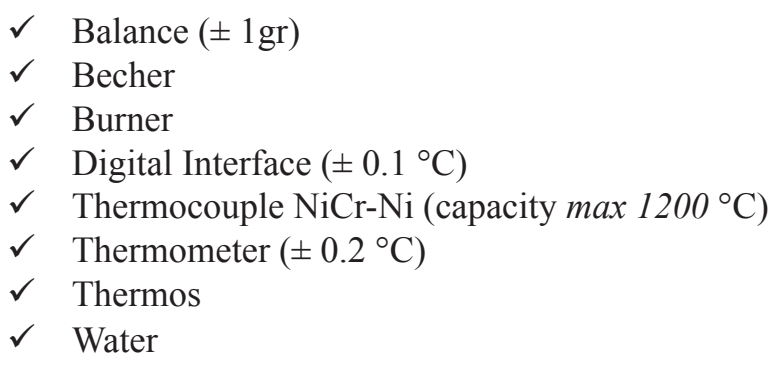

The experience aims to measure the water temperature cooling and to estimate the corresponding-modellized cooling curve. The standard conditions are ambient temperature and $1 \mathrm{~atm}-$ pressure $^{3}$.

We introduce a known mass of water $m_{a}$ and the thermometer (thermocouple) in the Becher until the water reaches its boiling point $T_{i}^{a}=100^{\circ} \mathrm{C}$ : it is the initial temperature. At this point the burner is turned off and we begin to measure the cooling temperature at regular intervals, for example every three minutes. At this stage a problem solving is appreciated: asking to students, they respond that the final temperature of the water will be equal to the ambient temperature, about $15-20^{\circ} \mathrm{C}$. In the meantime, we can observe and report the trend of the cooling curve in a graph (Descartesian-non-monometric diagram) on millimetric paper. This evokes a something, a function, whose trend is not linear.

2 The experiments described in the text have been carried out by one of the author (RP) within secondary schools. We used International System of Units (S.I.), but in order to let read our paper by also non-physical-specialists we used common units (e.g., for temperatures).

$31 \mathrm{~atm} \approx 1 \times 10^{5} \mathrm{~Pa}$ in SI.

4 In the experiment the thermal dispersion has been neglected. Furthermore we have supposed that the system metal-water is isolated. 
PROBLEMS

OF EDUCATION

IN THE $21^{\text {st }}$ CENTURY

Volume 50,2012

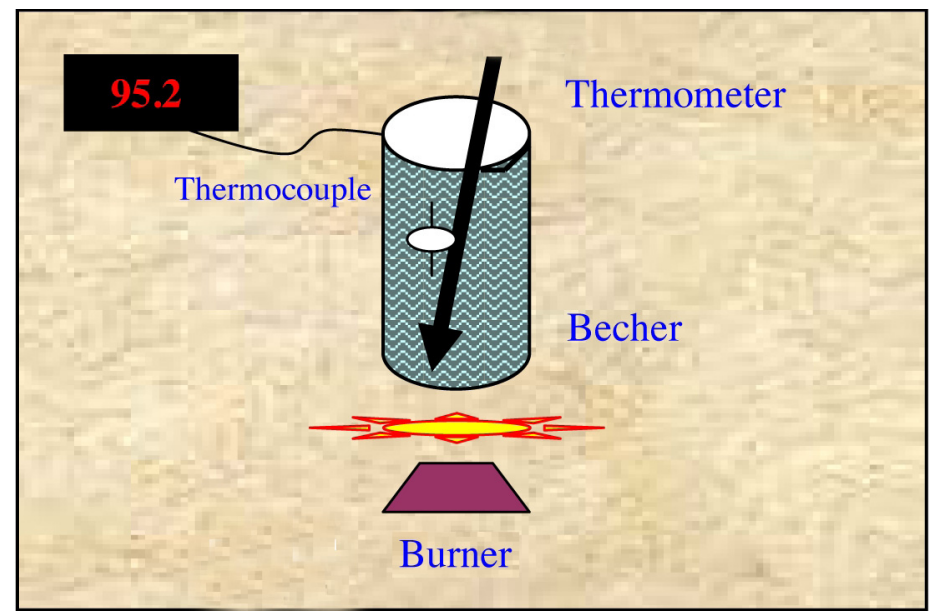

Figure 2: Experimental equipment.

\section{Results of the Research}

As said above, the experiment carried out in a secondary school and focused on the water behaviour while cooling. The final aim is the graphical elaboration of the curve which puts in relation temperatures and time (the time is represented on the $x$-axis and the temperature on the $y$-axis). The ambient temperature is $15.7^{\circ} \mathrm{C}$ and we have used a digital thermometer to control it. This instrument is formed by a thermocouple NiCr-Ni. At the margins of the thermocouple, a potential difference is created.

In the first step, the water reaches its boiling temperature $\left(\approx 100^{\circ} \mathrm{C}\right)$; after that, the burner is turned off and the water gets gradually cold until it reaches the thermal equilibrium with the ambient, according to the following scheme. The temperature is measured every three minutes. On the basis of the data measured, we wish to represents the diagrams putting in relation the temperatures and the time.

5 When the temperature of the water is near its boiling point, the measurement is subject to some irregularities and more refined means than those we could use are necessary. This is why the time 0 was established at temperature $69^{\circ}$. 
Raffaele PISANO, Paolo BUSSOTTI. Open Problems in Mathematical Modelling and Physical Experiments. Exploring Exponential Function

\begin{tabular}{|r|r|}
\hline \multicolumn{1}{|l|}{$\left.{ }^{\circ} \mathbf{C}\right)$} & \multicolumn{1}{l|}{ (minute $)$} \\
\hline 69 & 0 \\
\hline 66,5 & 3 \\
\hline 57,8 & 6 \\
\hline 52,8 & 9 \\
\hline 50 & 12 \\
\hline 46,9 & 15 \\
\hline 43,8 & 18 \\
\hline 41 & 21 \\
\hline 38 & 24 \\
\hline 36 & 27 \\
\hline 34 & 30 \\
\hline 31 & 33 \\
\hline 30,3 & 36 \\
\hline 29,4 & 39 \\
\hline 28,3 & 42 \\
\hline 27,2 & 45 \\
\hline 26,4 & 48 \\
\hline 25 & 51 \\
\hline 24,7 & 54 \\
\hline 23,8 & 57 \\
\hline 23,1 & 60 \\
\hline 22,5 & 63 \\
\hline
\end{tabular}

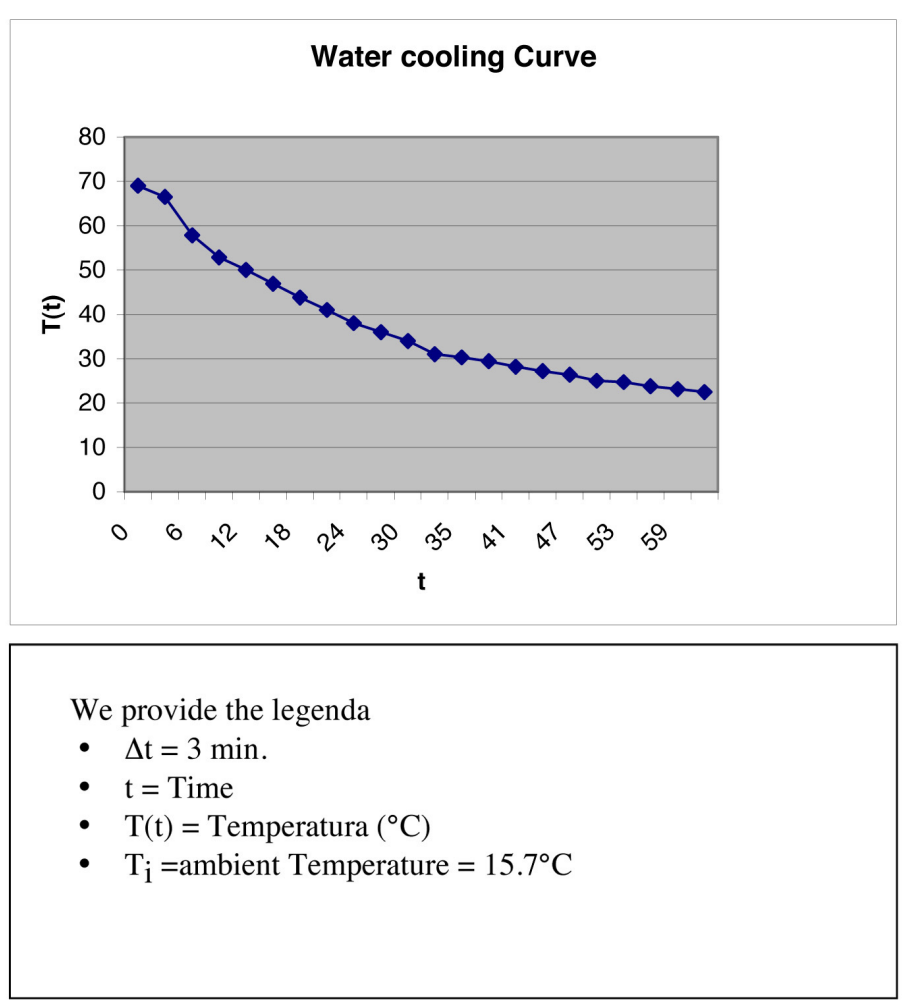

PROBLEMS

OF EDUCATION

IN THE $21^{\text {st }}$ CENTURY

Volume 50, 2012

61

Figure 3: Water cooling curve.

Once obtained the water cooling curve, another curve is proposed, where the difference $T_{i}-T_{f}$ (difference between the water temperature at a given time $t$ and the ambient temperature) is put on the $y$-axis.

\begin{tabular}{|r|r|}
\hline Ti-Tf(C) & t (min) \\
\hline 53,3 & 0 \\
\hline 44,8 & 3 \\
\hline 42,1 & 6 \\
\hline 37,1 & 9 \\
\hline 34,3 & 12 \\
\hline 31,2 & 15 \\
\hline 28,1 & 18 \\
\hline 25,3 & 21 \\
\hline 23,1 & 24 \\
\hline 20,3 & 27 \\
\hline 18,3 & 30 \\
\hline 15,3 & 33 \\
\hline 14,6 & 36 \\
\hline 13,7 & 39 \\
\hline 12,5 & 42 \\
\hline 11,5 & 45 \\
\hline 10,7 & 48 \\
\hline 9,3 & 51 \\
\hline 9 & 54 \\
\hline 8,1 & 57 \\
\hline 7,4 & 60 \\
\hline 6,8 & 63 \\
\hline & \\
\hline
\end{tabular}

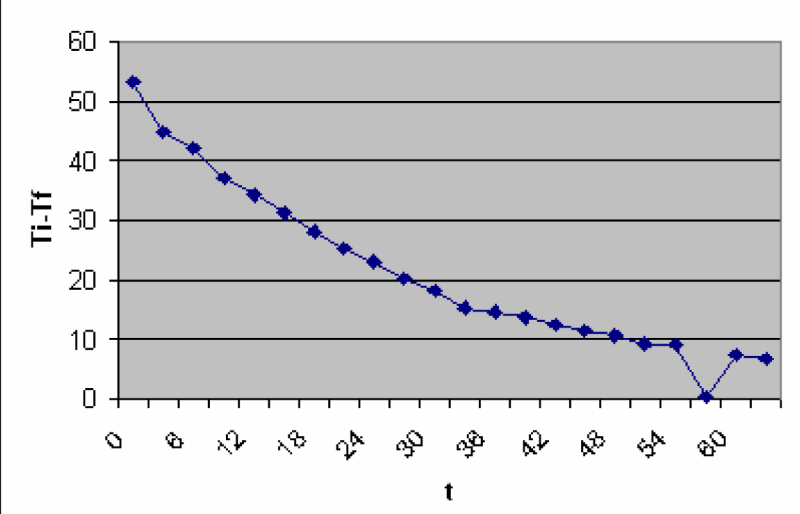

Figure 4: Water cooling curve (continue). 
PROBLEMS

OF EDUCATION

IN THE $21^{\text {st }}$ CENTURY

Volume 50, 2012

62

If now we replace the segments of straight line that unify the values obtained in the two diagrams, we obtain a continuous function whose trend is the following:

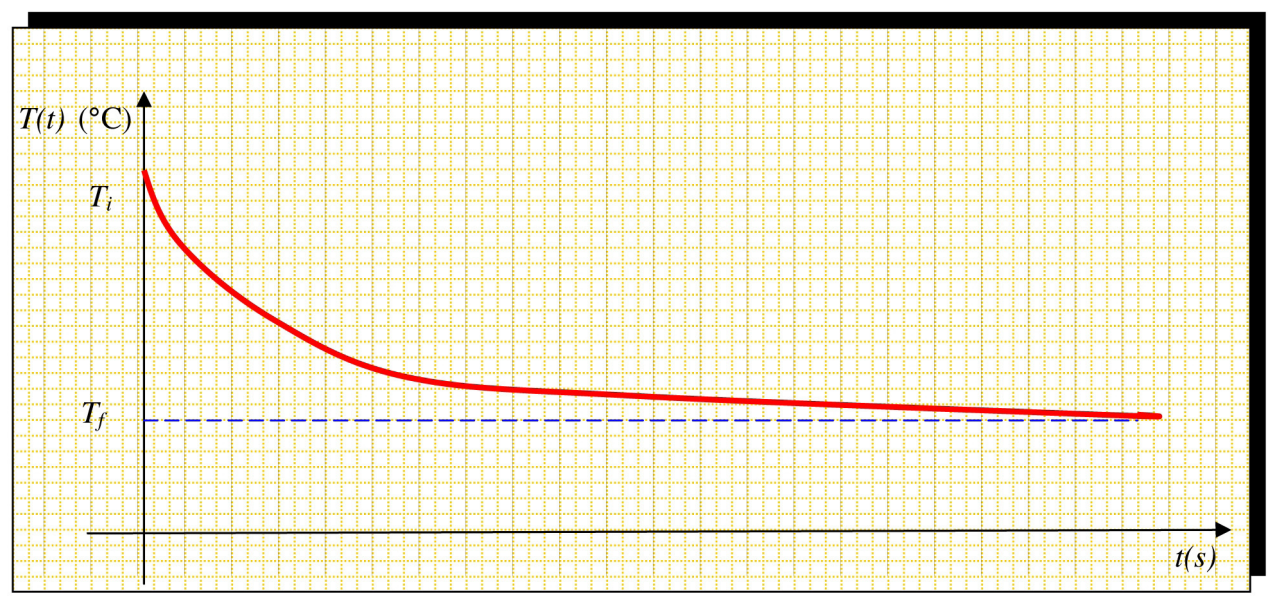

Figure 5: Water cooling curve modelled-theorized (continue).

After having traced the form of the function that expresses the phenomenon of the cooling water, we invite the students to reason on its properties: they immediately underline that the curve has a non linear decreasing trend and that tends to reach the straight line $T(t)=T_{f}$ (kind $y=k$ ) as asymptote. If one wishes to obtain an analytical expression for the curves of this kind, it is not necessary to introduce Euler number and we have proposed to examine the function

$$
y(x)=2^{-x}
$$

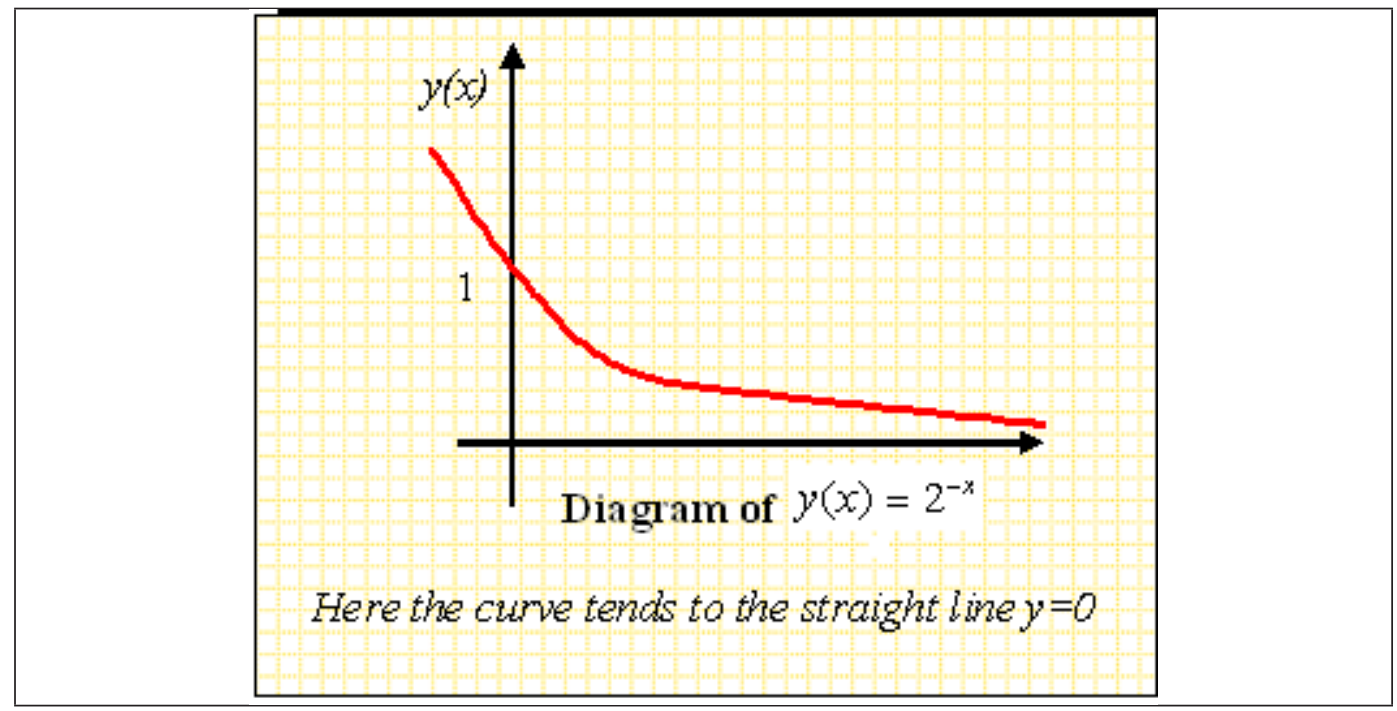

Figure 6: Mathematical modelling of the water cooling curve (continue). 
Substituting some values to $x$, it is easy to convince the students that the curve has the trend represented in the figure. However, some considerations are necessary: from a formal point of view, the straight line $T(t)=T_{f}$ in fig. 5 has the same role as the straight line $y=0$ in fig. 6: both of them are asymptotes and this is easily understood by the students, even if $T_{f} \neq 0$. Nevertheless, in fig. 5 the independent variable $t$ cannot be less than 0 because, according to the way in which we have conceived the experiment, it is absurd the existence of a time with negative sign. On the contrary, if our independent variable has its general form $x$, without any further specification, it is perfectly conceivable that $x$ is less than 0 . From a strictly mathematical point of view, nothing prevents us to put $x<0$, but it is absurd to put (in our case) $t<0$. This is important in a didactical and epistemological perspectives: physics has more restrictive conditions than mathematics because physics has to respect with its correlations between numbers and physical significances (e.g., what does it mean a negative number in physics? Or a list of number after comma?); rather that implies that physical-mathematical modelization. On the other hand, the comparison between physical exponential function and mathematical exponential function is so the occasion to clarify the students the concept of mathematical rigour: for a physician if we have an enough regular series of points with a certain trend, it is in order to complete this series with a continuous line and this is perfect for the physical treatment. However, from a rigorous mathematical point of view this does not work because nobody ensures us that some irregularities occur in the infinite points we have not controlled. This is why it is necessary to introduce the concept of continuous function in analytical terms. It is not needed to do that in the classroom, but the students have to clearly catch the similarities and the differences between physics and mathematics. Our experiment involving exponential function looks particularly suitable for this aim.

Further other considerations are possible: let us consider a geometrical transformation of the function $y(x)=2^{-x}$, in particular a translation downwards of the quantity $T_{f}$, according to the system:

$$
\mathrm{t}_{y}:\left\{\begin{array}{l}
x^{\prime}=x \\
y^{\prime}=y-y_{0} \rightarrow T(t)-T_{f}=0
\end{array}\right.
$$

The students understand without

difficulty that this transformation represents the function $T(t)-T_{f}$

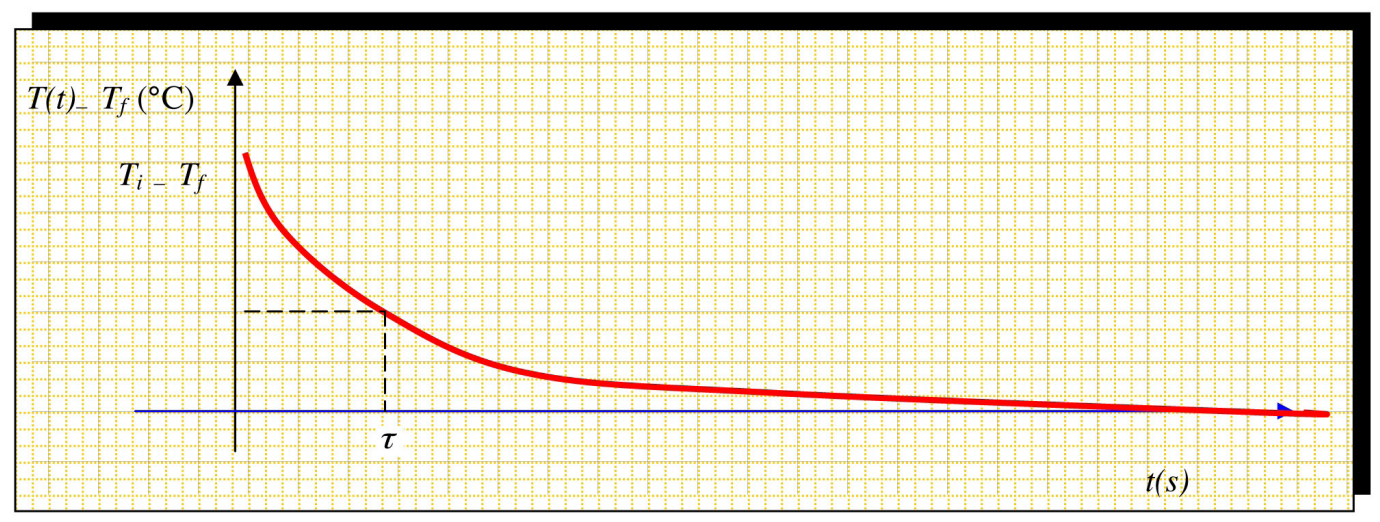

Figure 7: Water cooling curve modelled-theorized (continue). 
ROBLEMS

OF EDUCATION

IN THE $21^{\text {st }}$ CENTURY

Volume 50, 2012

We have a decreasing exponential function passing for the point $\left(0 ; T_{i}-T_{f}\right)$ and whose

horizontal asymptote is once again the straight line $T(t)-T_{f}=0$; but now this line is our $x$-axis $(y=0)$. This induces the students to reason on the fact that the graph of this exponential function, is modified by a factor $T_{i-} T_{f}$ because the exponential function $y=2^{-x}$ touches the $y$-axis in $(0,1)$, while the transformed function in $\left(0 ; T_{i}-T_{f}\right)$. This means that in general we can write:

$$
y(x)-y_{0}=\left(T_{i}-T_{f}\right) \cdot 2^{-x}
$$

On our side:

$$
T(t)-T_{f}=\left(T_{i}-T_{f}\right) \cdot 2^{-x}
$$

This is the function a student can assume describing the water cooling. The one we have exposed is only a simple example of a new possible approach to the methodology of mathematical teaching: the possibility to reach some general mathematical concepts, as the one of curve, of function, of geometrical transformation starting from examples drawn from physical experiments. This is an intuitive and "practical" approach which, in some cases can be rather helpful and advisable to overcome the difficulties of the formal one. Obviously after having caught the concepts from an intuitive point of view, the rigour is necessary, but the development of the intuitive faculties of the student and of its capability to work in an experimental way can help him to have a creative and participant approach to mathematics. Furthermore it is possible to construct in this way a positive link between the teaching of mathematics and physics, focusing on the analogy and the differences of the two disciplines.

In physics a significant aspect is the dimensional one. In our case, temperatures or differences of temperatures are represented on the $y$-axis and times are represented on the $x$ axis. Therefore, since in equation 3 ) the first member and the factor $T_{i-} T_{f}$ have the dimensions of a temperature, this means that the variable $x$ is a ratio of times, this means we have:

$$
T(t)-T_{f}=\left(T_{i}-T_{f}\right) \cdot 2^{-\frac{t}{t}}
$$

where $\tau$ represents a constant of the phenomenon having the dimensions of a time. A debate on the meaning of $\tau$ is followed in the class. For $t=\mathrm{t}$, the difference of temperature becomes the half of the initial one, according to the equation

$$
T(t)-T_{f}=\frac{\left(T_{i}-T_{f}\right)}{2}
$$

In an initial approach with this kind of problems, the value $\tau$ can be hence considered as a constant indicating the halving-time.

To summarize. Our work on the connection between the exponential function and the cooling water phenomenon has produced these specific results: 
- Geometrical transformations can help us to enucleate a physical function starting from an a priori known mathematical function.

- The modelling of a physical phenomenon in which it is possible to find some regularities (in this case the exponential trend) introduces to the formal study of the mathematical objects which are necessary to analyse the phenomenon itself.

- The exponential function describing the cooling and the heating of a substance is independent from the kind of substance.

- The exponential function fits perfectly to describe the thermal phenomena.

Therefore, the two initial results can be immediately deduced by what we have proposed to the students; as to the others, an interesting discussion on the relation between induction and deduction in physics mathematics can be proposed to the classroom. The cooling water curve is an exponential function; we could ask to the students if they think that:

1) Are the cooling and heating curves independent (in the form) from the cooling or heating substance?

2) Does the exponential function really fit to describe these phenomena?

A conclusion might be that, probably, the study of a sole phenomenon does not provide a sufficient basis to draw a general law. It is hence likely that the students ask for other data inherent to other thermal phenomena, we then should be able to provide them. In the classroom two other experiments were carried out: 1) water heating; 2) aluminium heating. In these cases, heating water curve and heating aluminium curve have been deduced by a technique akin to the one exposed for the cooling water curve. By means of an equipment similar to the one analysed, the temperature of the two substances was raised, the data were reported in a table every five minutes and a graphic was traced. Since the form of the heating curve is similar for water and aluminium, we refer water's one ${ }^{6}$.
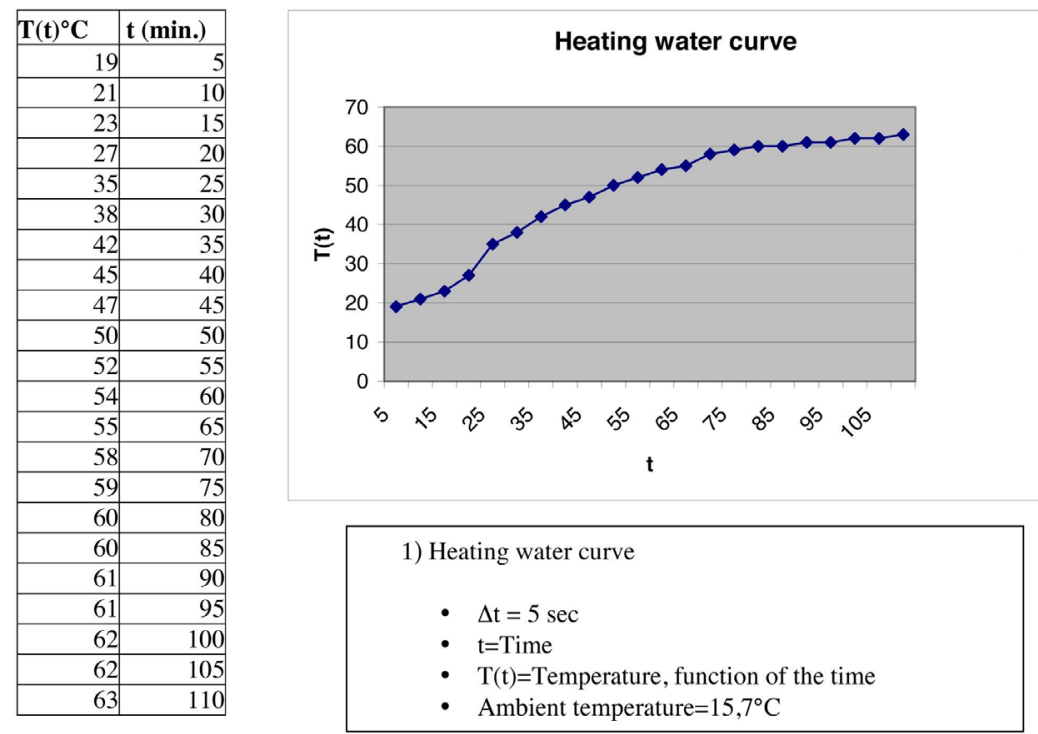

Figure 8: Heating water curve.

$6 \quad$ Figure 8 corresponds to figure 3 for the cooling phenomenon and figure 9 to figure 4 . 
PROBLEMS

OF EDUCATION

IN THE $21^{\text {st }}$ CENTURY

Volume 50, 2012

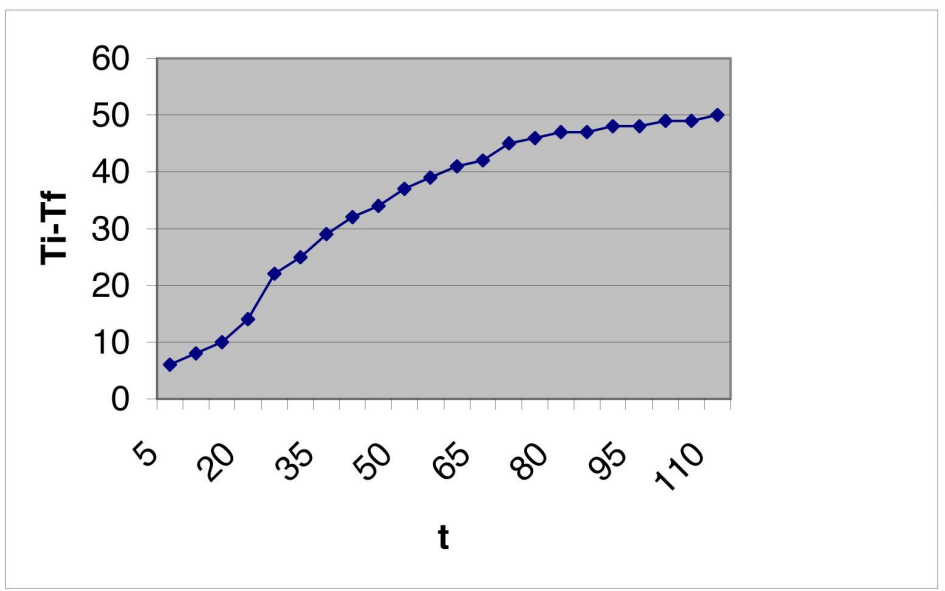

Figure 9: Heating water curve with in $\boldsymbol{y}$-axis the difference $T i$-Tf.

This curve is as interesting as the cooling curve for the problem of modelization. As a matter of fact, the cooling water curve can be used to introduce the exponential function in mathematics and, in particular, the exponential functions of the form $A^{-x}$ ( $A$ is a constant), while the heating curve can be used to introduce exponential functions of the form $A^{-\frac{1}{x}}$. Therefore, this physical experiments can be utilized not only to deal with exponential function, but with different types of exponential functions. It is interesting to extend the discussion in class to the functions $A^{x}$ and $A^{\frac{1}{x}}$. Thus, the teacher can ask the students for the form they expect this functions have and whether they think that some phenomena similar to those analysed can be expressed by the functions $A^{x}$ and $A^{\frac{1}{x}}$. In this manner, experiments that can be easily carried out provide a wide range of arguments that can be treated at high school. Part of the relations between physics and mathematics can be hence clarified basing on the experimental method.

\section{Conclusions}

Three examples in which thermal phenomena of cooling and heating can be modelised by an exponential function have been presented; one, the water cooling, has been analysed in depth. This can be considered a reasonable empirical basis to claim that the exponential function is a general model for this kind of phenomena. One of the main goals of our work is the interdisciplinary: this word is often used in didactics, but its meaning in frequently unclear. In our above cited experiments, we have already stressed the way in which our experiments and our considerations can connect physics to mathematics. The relation between scientific 
induction and deduction is also the way to approach methodology of physics, history of science and epistemology where, as we done, one example looked not sufficient to conclude that the cooling and heating phenomena have an exponential trend. Three experiments looked a reasonable number to draw some conclusions.

From this case, the teacher can generalize: what is the relation between induction and deduction in physics? How many experiments are necessary to be reasonably sure that a model can describe correctly a phenomenon?

Have the physical principles and laws been discovered in the history of science by generalizations of single results or have been they deduced more euclideo?

Is a general theory of the discovery possible or do the situations vary case by case?

With regard to induction-deduction a connection with epistemology is almost natural: Aristotle was the an important philosopher who first spoke of the relations and differences between induction and deduction and, after him, this theme has become a classical philosophical problem: it is possible to organize lessons with the teachers of physics and of history and philosophy to discuss the problem induction-deduction in its logical (philosophy) and physical (both physics and history of science) terms. In the secondary school it will be possible to provide only the general coordinates of such difficult and general questions, but this will be extremely stimulating for the students and maybe a step towards the humanistic value of the science will be made. Furthermore, this discussion on the exponential function is a good basis to directly analyse the work of the scientists, with all difficulties they meet in their research and they met in the history of science. An example connected to the exponential function is really remarkable: Galileo, in his initial studies on the uniformly accelerated motion, thought that the velocities were as the spaces ${ }^{7}$, only afterwards and as a consequence of his experiment, he reached the right conviction that the velocities are as the times. This historical example is useful to introduce a series of considerations on the link between mathematics-experiments in physics and on the role of mathematics inside physics: if we suppose that velocities are

as spaces, the solution of the differential equation $\frac{d s}{d t}=k s$, provide the solution $s=e^{k t}$, an exponential function. But, if the time is equal to 0 , the space is equal to 1 , this means that the space can never be 0 and hence this motion cannot begin. The solution of this differential equation was available for the mathematicians living in the second half of the end of the $17^{\text {th }}$ century, but it was not available to Galileo. Otherwise he could have excluded this law immediately, without further experiments and maybe he could have reached quicker the right law. However, independently of this last consideration, this historical example shows that in physics the links between mathematics and experiments is a difficult and variegated subject: experiments are necessary for the discovery of physical laws that, afterwards, are expressed in mathematical terms; but it also happens that mathematics knowledge can a guide for experiments, and the lack of certain mathematical knowledges can make the experimental part of physics complicated. This picture, with its history connected with the present progress of the research, is very fascinating. The exponential function and its experimental introduction can be an initial access-key to the picture.

7 We deduce this from a fragment written by Galileo in 1604 (National edition of Galileo's Works, vol. 8, pp. 373-following, and from a letter to Paolo Sarpi on 1604 (National edition, vol. 10, pp. 212-following). 


\section{PROBLEMS \\ OF EDUCATION \\ IN THE $21^{\text {st }}$ CENTURY \\ Volume 50, 2012 \\ 68 References}

Alvarez, C., Dhombres, J. (2011). Une histoire de l'imaginaire mathématiques. Vers le théorème fondamental de l'algèbre et sa démonstration par Laplace en 1795. Paris: Hermann, pp. VIIXXV.

Ball, D. L., Thames, M. H., \& Phelps, G. (2008). Content knowledge for teaching: What makes it special? Journal of Teacher Education, 59 (5), 389-407.

Bass, H. (2005). Mathematics, mathematicians and mathematics education. Bulletin of The American Mathematical Society, 42 (4), 417-430.

Boero, P., \& Guala, E. (2008). Development of mathematical knowledge and beliefs of teachers. In: Sullivan P., \& Wood, T. (Eds.), The International Handbook of Mathematics Teacher Education. Purdue University, USA: Sense Publishers, Vol. 1, p. 223-244.

Boero, P., Pedemonte, B., \& Robotti, E. (1997). Approaching Theoretical Knowledge Through Voices and Echoes: a Vygotskian Perspective. In: Proceedings of the $21^{\text {th }}$ Conference of the International Group for the Psychology of Mathematical Education, Pehkonen E. (Ed.), Vol. 2, Lahti: Research and Training Center. University of Helsinki, p. 81-88.

Bridgman, P., (1927). The Logic of Modern Physics, NY: MacMillan.

Capecchi, D., \& Pisano, R. (2010). Reflections on Torricelli's principle in mechanics. Organon, 42, 8198.

Carnot, S. (1824), Réflexions sur la Puissance Motrice du Feu sur les machinés propre à développer cette puissance. Paris: Bachelier.

Carnot, L. (1813), Réflexions sur la métaphysique du calcul infinitésimal. Paris: Courcier.

Debru, C. (1997). On the Usefulness of the History of Science for Scientific Education. Notes and Records of the Royal Society of London, 51 (2), 291-307.

Faraday, M. (1839-1855). Experimental Researches in Electricity, 3 vols. London: Taylor.

Fox, R. (1974). The rise and fall of Laplacian physics. Historical Studies in the Physical Sciences, 4, 89-136

Fourier, J. B. J. (1822). Théorie analytique de la chaleur. Paris: Firmin Didot, 1822, pp. Ixxij; Id., Oeuvre de Fourier, vol. I, op. cit.

Fourier, J.B.J (1807), Théorie de la propagation de la chaleur dans les solides. Nouveau Bulletin des Sciences par la Société philomathique de Paris, Tome I, pp. 112-116. (n. 6, mars 1808), Paris: Bernard, 1807; Id., Oeuvre de Fourier, Paris: Gauthier-Villars, 2 Vols., 1888-1890.

Freudenthal, H. (1973). Mathematics as an educational task. Dordrecht, Netherlands: Reidel.

Galileo, G. (1890-1909). Opere di Galileo Galilei. Firenze: Barbera Editore.

George, A., \& Velleman, D. J. (2002). Philosophies of Mathematics. Oxford: Blackwell.

Gillispie, C. C., Pisano, R. (2012). Lazare and Sadi Carnot. A Scientific And Filial Relationship. HMMseries. Dordrecht: Springer.

Lagrange, J. L. ([1788], 1888). Mécanique Analytique. In Oeuvres de Lagrange, Vol. 11. Paris: GauthierVillars.

Laplace, P. S. (1799-1825). Traité de Mécanique Céleste, 5 vols. Paris: Duprat.

Lakoff, G., \& Nunez, R. E. (2000). Where mathematics come from. NY: Basic Books.

Mach, E. ([1883], 2009). The science of Mechanics. NY: Barnes and Noble.

Maxwell, J. C. (1865). A dynamical theory of the Electromagnetic field. Philosophical Transactions of The Royal Society of London, CLV: 459-512.

Maxwell, J. C. (1873). A Treatise on Electricity and Magnetism. 2 vols. Oxford: The Clarendon Press.

Mellone, M., Pisano, R. (2012). Learning Mathematics in Physics Phenomenology and Historical Conceptual Streams. Problems of Education in the 21st Century, 46, 93-100.

Meltzoff, A. N., Kuhl, P. K., Movellan, J., \& Sejnowski, T. J. (2009). Foundations for a new science of learning. Science, 325 (5938), 284-288.

Nagel, E. (1961). The Structure of Science. NY: Harcourt-Brace \& World Inc.

Newton, I. ([1687], 1803). The Mathematical Principles Of Natural Philosophy, by Sir Isaac Newton. Translated into English by Motte, A. London: Symonds, vol. I.

Newton I., ([1704], 2003). Optics, Amherst, NY: Prometheus Book.

Osborne, J. S., \& Collins, S. (2003). Attitudes towards science: a review of the literature and its implications, International Journal of Science Education, 25 (9), 1049-1079. 
Raffaele PISANO, Paolo BUSSOTTI. Open Problems in Mathematical Modelling and Physical Experiments. Exploring Exponential Function

Pisano, R. (2013). History Reflections on Physics Mathematics Relationship In Electromagnetic Theory In: Barbin E., Pisano R., (Eds). The Dialectic Relation between Physics And Mathematics In The PROBLEMS OF EDUCATION IN THE $21^{\text {st }}$ CENTURY Volume 50, 2012 XIXth Century. Springer: Dordrecht, forthcoming

Pisano, R. (2010). On Principles in Sadi Carnot's Theory (1824). Almagest, 2, 128-179.

Pisano, R. (2006). La Science et la Hypothèse di J.H. Poincaré. Note epistemologiche. Rivista di Epistemologia didattica, 1, 279-300.

Pisano, R. (2009). On method in Galileo Galilei' mechanics. In: Hunger, H. (Ed.), Proceedings of ESHS $3^{\text {rd }}$ Conférence, Vienna: Austrian Academy of Science, p. 147-186.

Pisano, R. (2011a). Physics-Mathematics Relationship. Historical and Epistemological notes. In: Proceedings of the ESU 6 History And Epistemology In Mathematics Education Barbin, E., Kronfellner, M. \& Tzanakis, C. (Eds.). Vienna: Verlag Holzhausen GmbH-Holzhausen Ltd., p. 457-472.

Pisano, R. (2011b). Textbooks, Foundations, History Of Science and Science education. Problems of Education in the 21st Century, 35, 5-10.

Advised by Violeta Šlekiené, University of Siauliai, Lithuania

Received: November 20, 2012

Accepted: December 18, 2012

\begin{tabular}{|ll|} 
Raffaele Pisano & $\begin{array}{l}\text { Ph.D., Lecturer of History of Physics, SCité University of Lille1, France. } \\
\text { Head of the Research Centre for the Theory and History of Science, University of } \\
\text { West Bohemia in Pilsen, Czech Republic. } \\
\text { E-mail: pisanoraffaele@@iol.it }\end{array}$ \\
\hline Paolo Bussotti & $\begin{array}{l}\text { Ph.D., Editor, Commission for the Publication of the National Edition of Federigo } \\
\text { Enriques's Works, Via Paolo Lilla, 66, Livorno, 57122 Italy. } \\
\text { E-mail: paolo.bussotti@alice.it }\end{array}$
\end{tabular}

